\title{
LINGUAGENS FORMAÇÃO DE PROFESSORES EM COMUNIDADES DE indice APRENDIZAGEM
}

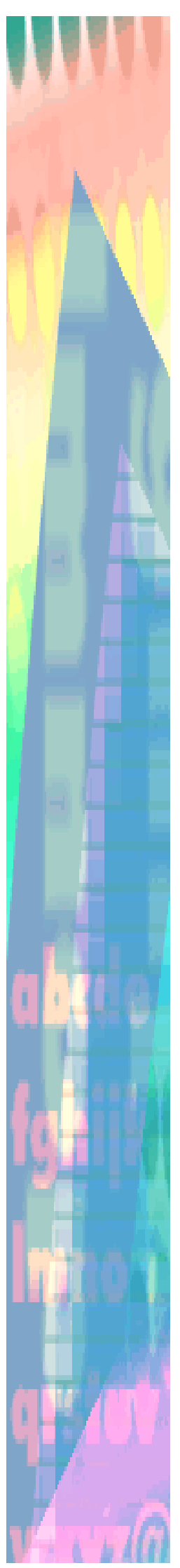

\author{
Fábio da Purificação de Bastos Claiton José Grabauska \\ Nedison Faria \\ Simone Girardi Andrade \\ Ilse Abegg
}

\section{INTRODUÇÃO}

Este trabalho iniciou com a implantação do Programa de Pós-Graduação na Universidade Federal de Santa Maria em 1996, na linha de investigação: Formação de Professores e suas Implicações na Prática Pedagógica. A preocupação temática era como acoplar a investigação e a ação na prática educacional no espaço escolar formal: da pré-escola ao pós-graduação.

A opção por atuar onde vivemos de fato a educação conjuga-se com o problema de investigação. Visando a solucionar os problemas da prática educativa informada, no escopo de um projeto pedagógico dialógico, vemos possibilidades para um agir educacional colaborativo. Isto exige a participação de quem realmente está vivendo a prática. Por isso, trabalhamos com docentes e discentes da rede escolar, como participantes ativos de uma comunidade crítica de aprendizagem. A finalidade é compreender e transformar as práticas.

Buscamos, nas práticas vividas, soluções para os problemas educativos que enfrentamos. Assumimos uma atitude prospectiva na investigação pedagógica. A meta é mudar a realidade escolar vivida. O desenvolvimento profissional a que estamos sujeitos tem sido balizado pelas concepções: educacional problematizadora de FREIRE (1983) e investigação-ação educacional emancipatória de CARR e KEMMIS (1986).

Com o intuito de potencializar mudanças efetivas nas práticas educativas, o presente trabalho, enquanto relatório parcial de um programa de investigação-ação educacional, aponta o potencial desta forma de organização do trabalho escolarcomo comunidade de aprendizagem-- também no plano das reestruturações curriculares na educação formal.

O framework deste trabalho considera os desenvolvimentos teórico-práticos em termos de educação dialógica e investigação-ação emancipatória do grupo que tem atuado em diversas instâncias da rede de ensino. São diversos projetos de pesquisa, com diversas problemáticas, nos níveis de iniciação científica, mestrado e doutorado, dados no âmbito da tríade ensino, pesquisa e extensão, que funcionam com caráter integrado uns com os outros. Estes são desenvolvidos desde a educação básica até a pós-graduação e todos já contam com publicações nacionais e, alguns, internacionais.

\section{FORMAÇÃO DE COMUNIDADES CRÍTICAS DE APRENDIZAGEM}

Pelo exposto, cabe-nos ressaltar que a preocupação temática do referido programa de investigação-ação educacional—que orienta o processo de investigação temática-, tem sido a formação de professores numa dada realidade educacional, sendo esta entendida como realidade concreta dos envolvidos no processo. Desta forma, segundo a acepção freireana de realidade concreta, tem sido fundamental para o quefazer educativo do grupo investigar e mapear as visões de mundo dos envolvidos e suas práticas educativas, colaborativamente com eles. 
Portanto, o processo de ensino-aprendizagem prioriza a apreensão, tanto de teoriasguia que informam as práticas, quanto das próprias práticas educativas e dos contextos onde ocorrem. Dito de outra forma, o conhecimento prático ou do ofício dos professores é, também, objeto cognoscente a ser problematizado e apreendido no processo educacional. Assim, a formação de comunidades críticas e de professores situam-se no mesmo plano. O que implica a organização de grupos de investigaçãoação educacional, ou seja, sujeitos educativos, que concomitantemente investigam ativamente no contexto escolar, onde assumem papéis de educador-educando e educando-educador.

No âmbito da investigação-ação educacional emancipatória, o grupo assume a responsabilidade pelos ditames da irracionalidade, da injustiça, da alienação e da falta de auto-realização. Como objetos desta investigação adotamos os hábitos, as tradições, as estruturas de controles e as rotinas burocráticas, com o intuito de identificar os aspectos da educação vivida e que caracterizam a realidade concreta, permitindo-nos transformá-la. Esta concepção de investigação apoia-se na teoria do conhecimento habermasiana que possui interfaces com a perspectiva educacional dialógica freireana. Trata-se da conjugação da prática educacional dialógica, tendo como pano de fundo a educação como prática para a liberdade, no contexto da investigação-ação emancipatória.

\section{TEORIA DO CONHECIMENTO EMANCIPATÓRIA}

Resumidamente, podemos afirmar que a concepção epistemológica presente distingue conhecimentos técnico, prático e emancipatório num contexto comunicativoativo, cujo intuito de comunicar a razão ressalta o sujeito do ponto de vista éticocrítico. Isto implica considerar a interação humana como um processo de devir, onde o esclarecimento colocado vai além da visão iluminista. Por outro lado, FREIRE (1983, 1992) considera o par contraditório bancário-dialógico na díade opressoroprimido, cujo intuito é a produção do ser mais através de ações culturais para a libertação.

Neste contexto do agir comunicativo e da ação dialógica e problematizador, a dinâmica codificação-descodificação passa a configurar a prática educativa em termos dos momentos indissociáveis do ensinar-aprender: investigação-ação acoplada à redução-temática. Trata-se de investigar ativamente no processo escolar!

\section{MOMENTOS METODOLÓGICOS}

Temos implementado na prática educativa os momentos metodológicos da investigação-ação, segundo os passos - planejamento, ação, observação e reflexão - que formam a espiral reflexiva de origem lewiniana (CARR e KEMMIS, 1986).

Inicialmente desenvolvemos um planejamento escolar envolvendo ativamente os educandos nas atividades educacionais a serem desenvolvidas na sala de aula. Fazse esta tarefa especificando a cada hora-aula, para que lhes seja inviável retornar à sua rotina escolar. Em seguida, desenvolvemos, colaborativamente, com os envolvidos no processo educacional, as atividades educacionais planejadas, procurando registrá-las a cada hora-aula. Deste modo, temos subsídios para a etapa reflexiva, cujo caráter avaliativo-deliberativo reorientará os planejamentos educacionais seguintes.

Resumindo, ao ingressarmos no processo educacional, via espiral reflexiva que caracteriza uma investigação-ação, parametrizamos o fazer escolar por uma dinâmica pautada pela codificação-descodificação dos conhecimentos científicos. Nesta instância, concretiza-se a interface com projetos integrados, especificamente da informática, que têm contribuído com a dinâmica de investigação ativa nas aulas, através do suporte científico-tecnológico presente, por exemplo, nos textos eletrônicos disponíveis na internet (Projetos Integrados de pesquisa "Criando Desafios na Informática" e "Redes e Conhecimento Científico na Escola", ambos em 
desenvolvimento e financiados pelo CNPq.)

É desta forma que a educação problematizadora sintoniza os sujeitos no mundo com os avanços científicos e tecnológicos de seu tempo. Trata-se de assumir que cultura científica é também composta pela cultura informática, evidenciando-se o fazer científico como um agir em redes. Redes e conhecimento científico, ausentes, ainda, nesta virada de século na escola. Diante disto, é urgente criar desafios educacionais em informática na escola!

Um programa de investigação-ação educacional, nesta perspectiva, possui duas instâncias bidimensionais: construtiva e reconstrutiva, numa, teórico, e prático em outra. O planejamento, etapa inserida na instância construtiva e na dimensão teórica, é o momento em que os participantes do programa planejarão a ação prospectiva. Deve ocorrer após a delimitação de uma preocupação temática. Após o estabelecimento do planejamento, o grupo parte para a ação. Um ato individual informado. Isto, por outro lado, não significa que esta perspectiva de investigação seja fundada numa proposta de planejamento acabada, que não pode, nem deve sofrer adequações. Ao contrário disto, esta deve ser vista como sendo uma variação cuidadosa e reflexiva da prática e que está informada criticamente quanto ao seu propósito educativo.

A observação ocorrerá durante a ação, objetivando documentá-la. Registrar os acontecimentos que servirão de base para as reflexões. Está inserida na instância de reconstrução, de algo construído e ocorrido na prática.

A reflexão é o momento em que nos debruçamos sobre os dados da observação, prática documentada e o planejamento. Portanto, é uma reflexão na ação. É nesta etapa que ponderamos e avaliamos todos os momentos — individual e coletivo — da investigação-ação educacional. Devemos, portanto, entender a reflexão em função das auto-reflexões, no sentido em que participa, através da comunicação competente dos envolvidos, na construção de uma prática mais racional, considerando os problemas iniciais dos quais deflagraram o processo cíclico de investigação-ação educacional.

Para KEMMIS (1999), a reflexão é um ato político dado na direção de construir uma sociedade mais racional, prudente e satisfatória. Portanto, é social, processual, está orientada para a ação e tem inscrição histórica (não fica reduzida a uma função psicológica), forma a ideologia e é formada por ela e, principalmente, é uma prática que carrega um exercício de poder na reconstrução da sociedade pela comunicação, tomada de decisões e ações sociais. Tem seu suporte na trama da dupla dialética: pensamento-ação e indivíduo-sociedade.

Tais características permitem o refinamento da compreensão sobre a importância da formação profissional operacionalizada em comunidades de aprendizagem, para o interesse emancipatório, uma vez que os embates dialógicos entre os envolvidos permite a argumentação e a contra-argumentação nos momentos de planejamento, construtivos ou prospectivos, conforme explicitado anteriormente.

Para além do "olhar" e estudar as situações-problemas, compreender e transformar as situações-problemas identificadas no espaço educativo é, segundo nossa concepção, tarefa dos envolvidos no processo educacional numa perspectiva libertadora. Valorizar a aprendizagem auto-reflexiva, oriunda das observações da prática educativa, reorienta o desenvolvimento cognitivo e, portanto, profissional, dos professores. É por isto que assumimos como critério epistemológico o conhecimento da prática educativa, ou seja, o conhecimento do ofício profissional do professor. O que implica assumir a tarefa de ser mais no ato colaborativo do ensinar-aprender no presente histórico com potencial de transformação. É a produção da existência humana potencializando transformações na realidade concreta, vivida pelos seres no mundo. 


\section{DELINEAMENTOS E DESAFIOS}

A interação entre as concepções de formação de professores, investigação-ação educacional emancipatória e comunidade crítica de aprendizagem, construídas na prática pelo grupo, aponta como primeiros resultados de pesquisa a renucleação dos fundamentos pedagógicos nos cursos que formam os profissionais da educação. Não se trata aqui de discutir isoladamente, ensino e aprendizagem, organização escolar e didática, indivíduo e sociedade, teoria e prática e, até mesmo, política e educação. Ao contrário, busca-se a superação de tais falácias dicotômicas para um agir cientificamente informado pela racionalização crítica.

Um dos delineamentos apontados é o que acopla investigação e ação durante a formação inicial e continuada de professores, o que aproxima este enquadramento organizativo da proposta aventada pela comissão de especialistas do Ministério da Educação em nosso país. Ou seja, o trabalho desta comunidade de aprendizagem já encontra, além do científico, o respaldo institucional para seu estabelecimento e expansão.

Finalmente, parece que o desafio delineado em termos de formação de grupo de investigação-ação educacional como comunidade de aprendizagem coloca como tarefa formativa ou de desenvolvimento profissional a criação e expansão das mesmas. O que, não temos dúvidas, exige uma discussão dos valores da educação num contexto neoliberal como o que estamos vivendo. É preciso não aceitar esta realidade como o fim da história, pois, se assim agirmos e pensarmos estaremos fadados a um destino imposto: somos sujeitos, não objetos!

\section{BIBLIOGRAFIA}

CARR, W. e KEMMIS, S. Becoming Critical: Education, knowledge and action research, Brighton, UK:Falmer Press, 1986.

DE BASTOS, Fábio da P. \& GRABAUSKA, Claiton J. Investigação-Ação Educacional: possibilidades críticas e emancipatórias na prática educativa. In: Heuresis Revista Electrónica de Investigación Curricular y Educativa, vol.1, n.2, 1998.[on line] Disponível na internet via URL em http:/www2.uca.es/HEURESIS, Cadiz, España.

FREIRE, P. Pedagogia do oprimido. Rio de Janeiro: Paz e Terra, 1983.

Educação como Prática da Liberdade. Rio de Janeiro:Paz e Terra,1992

KEMMIS, S. La formación del profesor y la creación y extensión de comunidades críticas de profesores. In: Investigación en la Escuela, nº19, p.15-38, 1993.

. La Investigación-Acción y la Política de Reflexión. In: ANGULO RASCO, J.F. et alii (orgs.) Desarrollo Profesional del Docente: política, investigación y prática. Madrid: Ed. Akal, 1999.

[índice]

[ resumo ] 